\title{
Papers
}

\section{Moderate alcohol intake and lower risk of coronary heart disease: meta-analysis of effects on lipids and haemostatic factors}

\author{
Eric B Rimm, Paige Williams, Kerry Fosher, Michael Criqui, Meir J Stampfer
}

\begin{abstract}
Objective To summarise quantitatively the association between moderate alcohol intake and biological markers of risk of coronary heart disease and to predict how these changes would lower the risk. Design Meta-analysis of all experimental studies that assessed the effects of moderate alcohol intake on concentrations of high density lipoprotein cholesterol, apolipoprotein A I, fibrinogen, triglycerides, and other biological markers previously found to be associated with risk of coronary heart disease.

Participants Men and women free of previous chronic disease and who were not dependent on alcohol. Studies were included in which biomarkers were assessed before and after participants consumed up to $100 \mathrm{~g}$ of alcohol a day.
\end{abstract}

Interventions Alcohol as ethanol, beer, wine, or spirits.

Main outcome measures Changes in concentrations of high density lipoprotein cholesterol, apolipoprotein A I, Lp(a) lipoprotein, triglycerides, tissue type plasminogen activator activity, tissue type plasminogen activator antigen, insulin, and glucose after consuming an experimental dose of alcohol for 1 to 9 weeks; a shorter period was accepted for studies of change in concentrations of fibrinogen, factor VII, von Willebrand factor, tissue type plasminogen activator activity, and tissue type plasminogen activator antigen.

Results 61 data records were abstracted from 42 eligible studies with information on change in biological markers of risk of coronary heart disease. An experimental dose of $30 \mathrm{~g}$ of ethanol a day increased concentrations of high density lipoprotein cholesterol by $3.99 \mathrm{mg} / \mathrm{dl}$ (95\% confidence interval 3.25 to 4.73 ), apolipoprotein A I by $8.82 \mathrm{mg} / \mathrm{dl}$ (7.79 to 9.86 ), and triglyceride by $5.69 \mathrm{mg} / \mathrm{dl}$ (2.49 to 8.89 ). Several haemostatic factors related to a thrombolytic profile were modestly affected by alcohol. On the basis of published associations between these biomarkers and risk of coronary heart disease $30 \mathrm{~g}$ of alcohol a day would cause an estimated reduction of $24.7 \%$ in risk of coronary heart disease.

Conclusions Alcohol intake is causally related to lower risk of coronary heart disease through changes in lipids and haemostatic factors.

\section{Introduction}

The inverse association between moderate alcohol intake and coronary heart disease is documented in over 40 prospective studies in diverse populations. ${ }^{1-5}$ Men and women who consume one to three drinks a day have a $10 \%$ to $40 \%$ lower risk of coronary heart disease than those who abstain. In most large studies risk of coronary heart disease decreases in a downward linear fashion with alcohol intake up to three drinks a day. ${ }^{6-9}$ This reduction is generally attributed to the beneficial effects of alcohol on lipids and haemostatic factors. ${ }^{510-13}$

Over 75 experimental studies have examined the effects of alcohol intake on lipids, haemostatic factors, vitamins, glucose, insulin, and lipid peroxidation..$^{10 \mathrm{w} 1 \mathrm{w} 55}$ However, only a few epidemiological studies have simultaneously examined the relation between alcohol intake, biochemical variables, and subsequent risk of coronary heart disease. ${ }^{\text {w56-w61 }}$ From these studies it is estimated that half of the beneficial effect of moderate alcohol intake is due to increased high density lipoprotein cholesterol concentrations. This calculation may, however, be an underestimate because it does not take into account measurement error in the assessment of average alcohol intake or biological variability in high density lipoprotein cholesterol concentrations. In several of these studies potential confounding by other lifestyle factors-for example, diet, obesity, and physical activity-was also not considered. Furthermore, other biochemical variables, such as fibrinogen, triglycerides, von Willebrand factor, and insulin, were not examined in these simultaneous models.

We quantitatively summarised the effects of alcohol on a variety of biomarkers from experimental studies using standard meta-analysis methods, and we projected the impact of those changes on risk of coronary heart disease using data from published studies relating biomarker concentrations to coronary heart disease.

\section{Methods}

We searched Medline for all experimental studies of alcohol (ethanol) in humans published in English between 1965 and 1998. We supplemented our search by examining citations in review articles, ${ }^{13} 14$ the pro-
Department of Nutrition, Harvard School of Public Health, Boston,

MA 02115, USA

Eric B Rimm associate professor Kerry Fosher research assistant Meir J Stampfer professor

Department of Biostatistics,

Harvard School of Public Health

Paige Williams associate professor

San Diego School of Medicine and Family and

Preventive

Medicine,

University of

California at San

Diego, CA 92093

USA

Michael Criqui

professor

Correspondence to: E B Rimm eric.rimm@channing. harvard.edu

BMJ 1999;319:1523-8

website

extra

Additional references and details of the studies appear on the BMJ's website

www.bmj.com 
ceedings of meetings and symposia, and the Journal of the Alcohol Beverage Medical Research Foundation and Alcohol Research-journals that track alcohol related research. We restricted our search to studies in individuals without diagnosed coronary heart disease, diabetes, or alcohol dependence. We included only those studies that assessed biomarkers consistently modified by alcohol and related to risk of coronary heart disease. For lipid factors we included only studies with an intervention period of at least seven days; shorter intervals seem to have little or no effect. We included all studies of coagulation and thrombolytic factors because effects have been documented within hours after consumption of alcohol. Although we describe studies of lipid peroxidation and platelet aggregation we did not include these in our quantitative analyses because these assays were not comparable across studies owing to major differences in methodology. Furthermore, most were assessed with in vitro assays, which have not consistently been linked to risk of coronary heart disease.

In the final analysis we included only studies that provided the number, age range, and sex of the participants, average dose of alcohol, duration of the study, beverage type (beer, wine, spirits, or ethanol), and the change in concentration of a biological marker compared with its pretreatment measurement or a comparable group of placebo or untreated participants. Data were abstracted by two of the authors, and differences were resolved through consultation.

We excluded studies where $\geqslant 100 \mathrm{~g}$ of ethanol were consumed a day. For studies with multiple doses or multiple subpopulations we abstracted a data record from each study subpopulation. If ethanol was provided on the basis of the participant's weight we calculated the amount of ethanol for the average weight of the study participants. In several studies alcohol was given within strata of obesity or physical activity. These factors were considered as potential modifiers of the underlying relation between ethanol and biological variables of coronary heart disease. In our analysis each subpopulation was considered as a separate data record.

\section{Statistical methods}

For each biological measure we fitted a zero intercept weighted linear regression model predicting the change in the biological marker for alcohol intake as a continuous variable. We fitted intercept models and models with higher order terms, but the results were not appreciably different from our main analyses and are not presented. Each study was weighted by the inverse of the variance of the change measure. If no variance measure was provided we computed the average weight from the remaining studies. For biological markers with fewer than 10 data records we weighted the regressions by the size of the study. Using other weighting schemes did not substantially change the main results.

Consistent with standard meta-analysis techniques we treated study (or subpopulation within study) as a random effect, inducing a mixed effects model structure. The weighted least squares regression analyses were performed with a proc mixed procedure (version 6.12, SAS Institute, Cary, NC) using the biological marker as the dependent variable and dose of alcohol, age, sex, beverage type, and duration of study as the independent variables (fixed effects). In testing significance of each of the fixed effects we used Sattenthwaite's approximation to the degrees of freedom. ${ }^{16}{ }^{17}$

To estimate quantitatively the effect of alcohol on each biological marker we calculated the predicted mean change after an intake of $30 \mathrm{~g}$ of alcohol a day. Previously published studies linking each biomarker to risk of coronary heart disease were used to calculate the predicted relative risk of coronary heart disease that would be expected on the basis of the change in each biomarker achieved by consuming two drinks a day. Any association between a single biological measure and risk of coronary heart disease will usually be an underestimate of the true effect because of random error in biological measures owing to within person variability. ${ }^{18}{ }^{19}$ To evaluate the influence of measurement error on our results we used previously published estimates of components of variation in biological measures $^{2021}$ to adjust the predicted relative risks for this error.

\section{Results}

After exclusions we reviewed 42 experimental studies of alcohol, providing 67 separate data records. For the main analysis we excluded six data records from studies in which participants who usually consumed alcohol were restricted from any intake for several weeks, because the baseline measure of alcohol is less precise than in studies in which standard amounts of alcohol were given.

\section{High density lipoprotein cholesterol}

Results on change in high density lipoprotein cholesterol concentrations were available from 36 data records from 25 studies (see table A on website). After consumption of an average $40.9 \mathrm{~g}$ of alcohol a day for 4.1 weeks, high density lipoprotein cholesterol concentrations increased by an average of $5.1 \mathrm{mg} / \mathrm{dl}$. In an unweighted regression model high density lipoprotein cholesterol concentrations increased by $0.122 \mathrm{mg} / \mathrm{dl}$ per gram of alcohol a day (fig 1). After weighting each study as described high density lipoprotein cholesterol concentrations increased by $0.133 \mathrm{mg} / \mathrm{dl}$ per gram of alcohol consumed a day. The average individual consuming $30 \mathrm{~g}$ of alcohol a day would expect an increase in high density lipoprotein cholesterol concentration of $3.99 \mathrm{mg} / \mathrm{dl}(95 \%$ confidence interval 3.25 to 4.73) compared with an individual who abstains-an $8.3 \%$ increase from pretreatment values (fig 2).

Although we observed no significant confounding or modification of the effects of alcohol on high density lipoprotein cholesterol concentration by sex, duration of study, median age, or beverage type we did find some qualitative differences. Among men (29 records) the coefficient for a $1 \mathrm{~g}$ increase in alcohol was stronger $(\mathrm{b}=0.134 \mathrm{mg} / \mathrm{dl})$ than in women (three records) $(\mathrm{b}=0.095 \mathrm{mg} / \mathrm{dl}$; interaction, $\mathrm{P}=0.93)$. Among five studies with average baseline high density lipoprotein cholesterol concentrations below $40 \mathrm{mg} / \mathrm{dl}$ the effect of alcohol was stronger $(b=0.138)$ than among the 18 studies with concentrations above $48 \mathrm{mg} / \mathrm{dl}(\mathrm{b}=0.110$; interaction, $\mathrm{P}=0.04)$. Among the five studies that 


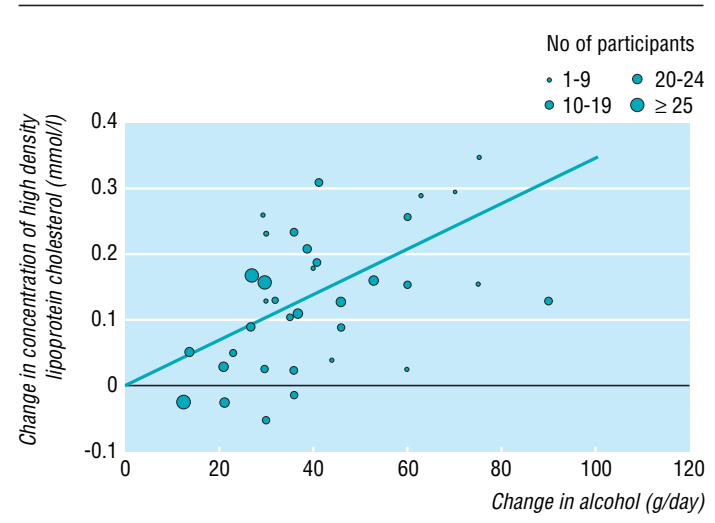

Fig 1 Weighted regression analysis of alcohol and high density lipoprotein cholesterol concentration from 36 data records abstracted from experimental studies of alcohol intake

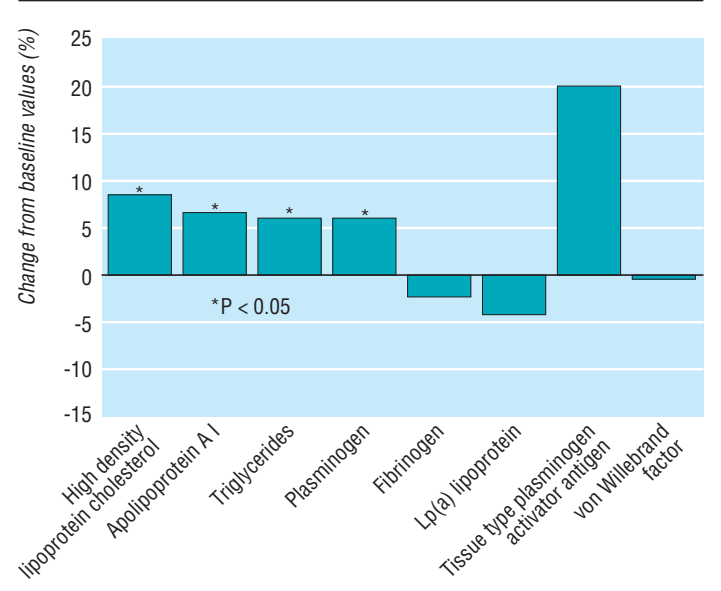

Fig 2 Percentage change in biomarkers associated with intake of $30 \mathrm{~g}$ of alcohol a day

selected physically fit participants the effect of alcohol was weaker $(b=0.108)$ than in the four studies of sedentary participants $(\mathrm{b}=0.190$; interaction, $\mathrm{P}=0.45)$. The coefficients for alcohol from beer $(b=0.160 ; 13$ studies), wine $(\mathrm{b}=0.132 ; 11)$, and spirits $(\mathrm{b}=0.111 ; 4)$ were not significantly different from each other or from the coefficient among the remaining studies that provided either ethanol or non-specific alcohol containing beverages $(\mathrm{b}=0.128 ; 8)$.

\section{Apolipoprotein A I}

An average of $37.6 \mathrm{~g}$ of alcohol a day was consumed for 3.9 weeks resulting in an increase in apolipoprotein A I concentrations of $11.83 \mathrm{mg} / \mathrm{dl}$. After weighting each of the 24 data records we found a $0.294 \mathrm{mg} / \mathrm{dl}$ increase in apolipoprotein A I concentrations per gram of alcohol consumed a day $(\mathrm{P}<0.001)$. The average individual consuming $30 \mathrm{~g}$ of alcohol a day showed an $8.82 \mathrm{mg} / \mathrm{dl}$ (7.79 to 9.86$)$ increase in apolipoprotein A I concentrations (6.5\% increase over baseline; fig 2).

\section{Triglycerides}

From 35 data records we found that triglyceride concentrations increased by $0.19 \mathrm{mg} / \mathrm{dl}$ per gram of alcohol consumed a day $(P=0.001)$ and $5.69 \mathrm{mg} / \mathrm{dl}$
(2.49 to 8.89$)$ per $30 \mathrm{~g}$ consumed a day ( $5.9 \%$ increase over baseline; fig 2).

The coefficient for alcohol was stronger among the 26 studies in men $(\mathrm{b}=0.22 ; \mathrm{P}=0.003)$ than among the three studies in women $(\mathrm{b}=-0.09 ; \mathrm{P}=0.41)$, but the small number of studies conducted only among women limits our power to observe differences. The coefficient for 11 studies with only beer $(b=0.27)$ was slightly stronger than the coefficient for 11 studies with only wine $(b=0.20)$ and for six studies with only spirits $(b=0.17)$, but the differences were not significant.

\section{Other factors}

Alcohol intake has been associated with a favourable thrombolytic profile in many cross sectional studies $^{121322-25}$ and in several experimental studies (see table B on website). Many studies have used in vitro or ex vivo measures of platelet aggregation, but assay methods vary greatly and few such markers have been linked with risk of coronary heart disease. Only a few studies have assessed concentrations of fibrinogen, plasminogen, tissue type plasminogen activator, plasminogen activator inhibitor-1, factor VII, and von Willebrand factor (see table B on website)-factors that have been associated with risk of coronary heart disease. ${ }^{26-28}$ Weighted regression analyses for each of these haemostatic factors was suggestive of a more thrombolytic profile, but none was significantly affected by moderate alcohol intake (fig 2). From the weighted regression equations an increment of $30 \mathrm{~g}$ of alcohol a day was associated with a $7.5 \mathrm{mg} / \mathrm{dl}(-17.7$ to 32.7 ) decrease in fibrinogen concentration, a 1.25 $\mathrm{ng} / \mathrm{ml}(-0.31$ to 2.81$)$ increase in tissue type plasminogen activator antigen concentration, and a $1.47 \%(-1.18$ to 4.42$)$ increase in plasminogen concentration. Lp(a) lipoprotein-a lipoprotein particle that may affect the fibrinolytic cascade-was only assessed in four studies (five data records) and was modestly, and non-significantly, decreased by 0.70 $\mathrm{mg} / \mathrm{dl}$ ( -3.38 to 1.99$)$ for each $30 \mathrm{~g}$ increment of alcohol a day. We did not include activity of tissue type plasminogen activator owing to substantial differences in assay methods and heterogeneity of results. Furthermore, it is not clear that acute changes in tissue type plasminogen activator caused by alcohol intake should be used to determine subsequent risk of coronary heart disease because concentrations may also be influenced by extent of existing coronary disease. ${ }^{27}$ Sufficient data were not available to calculate a weighted average for von Willebrand factor or factor VII, but alcohol tended to lower the concentrations of both. ${ }^{\text {w37 w50 }}$

The effect of alcohol on many other biochemical variables (for example, insulin, glucose, carotenoids, folate, lipid peroxidation, low density lipoprotein cholesterol, apolipoprotein B) has been assessed, but we excluded from this analysis those risk factors that had not been consistently found to be altered by alcohol, for which fewer than four data records were available, or that had not been consistently linked to risk of coronary heart disease.

Quantitative prediction of reduction in coronary heart disease risk among moderate drinkers

Using the effect sizes estimated for a $30 \mathrm{~g}$ increase in alcohol intake a day and results from studies of 
Projected percentage reduction in risk of coronary heart disease attributed to effects of alcohol on concentrations of high density lipoprotein cholesterol, fibrinogen, and triglycerides

\begin{tabular}{|c|c|c|c|}
\hline \multirow[b]{2}{*}{ Biomarker } & \multirow[b]{2}{*}{$\begin{array}{l}\text { Relative risk }(95 \% \mathrm{Cl}) \text { from } \\
\text { published study }\end{array}$} & \multicolumn{2}{|c|}{$\begin{array}{l}\text { Projected reduction in coronary heart } \\
\text { disease associated with } 30 \mathrm{~g} \text { alcohol } \\
\text { per day versus abstaining (\%) }\end{array}$} \\
\hline & & Unadjusted & $\begin{array}{c}\text { Adjusted for } \\
\text { intraindividual variability }\end{array}$ \\
\hline $\begin{array}{l}\text { High density lipoprotein } \\
\text { cholesterol }\end{array}$ & 0.69 (0.47 to 0.99$)$ per $10 \mathrm{mg} / \mathrm{dl}^{32}$ & 13.5 & 16.8 \\
\hline Fibrinogen & $1.34(1.15$ to 1.56$)$ per $50 \mathrm{mg} / \mathrm{dl}^{29}$ & 4.3 & 12.5 \\
\hline Triglycerides & $1.40(1.10$ to 1.77$)$ per $100 \mathrm{mg} / \mathrm{dl}^{33}$ & -1.9 & -4.6 \\
\hline Total & & 15.9 & 24.7 \\
\hline
\end{tabular}

biological markers and risk of coronary heart disease we computed the expected change in risk associated with consuming $30 \mathrm{~g}$ of alcohol a day compared with abstaining. No single epidemiological study has simultaneously calculated the risk of coronary heart disease associated with all biological markers. Therefore, we used several similar studies, ${ }^{269-31}$ which provided multivariate relative risk estimates for differences in concentrations of high density lipoprotein cholesterol, apolipoprotein A I, triglycerides, and fibrinogen (table).

The average increase in high density lipoprotein concentrations of $3.99 \mathrm{mg} / \mathrm{dl}$ for an intake of $30 \mathrm{~g}$ of alcohol a day would be associated with a risk reduction of $13.5 \%(4.3 \%$ to $24.2 \%)$ among men in the physicians' health study ${ }^{29}$; a similar reduction of $13.3 \%$ (10.6\% to $15.9 \%$ ) would be expected on the basis of results from the lipids research clinics study. ${ }^{32}$ If we adjust the effect estimate for intraindividual variability in high density lipoprotein cholesterol concentrations ${ }^{20}$ we estimate a $16.8 \%$ reduction in risk of coronary heart disease directly attributable to increased high density lipoprotein cholesterol concentration from consuming $30 \mathrm{~g}$ of alcohol a day. Because the effect of alcohol on high density lipoprotein cholesterol concentration was stronger in those with lower baseline concentrations the predicted $5.09 \mathrm{mg} / \mathrm{dl}$ increase for those with an average concentration of 35 $\mathrm{mg} / \mathrm{dl}$ would lower the risk of coronary heart disease by $20.9 \%$ after adjustment for intraindividual variability. Because concentrations of high density lipoprotein cholesterol and apolipoprotein A I are highly correlated, and the predicted reduction in risk was comparable for intakes of $30 \mathrm{~g}$ of alcohol a day, we assumed that the increase in concentrations of both markers were not independent and reflect the same biological phenomenon.

The small but consistent positive association between alcohol and triglyceride concentration may attenuate the benefits of alcohol. From the physicians' health study we project that the $5.69 \mathrm{mg} / \mathrm{dl}$ increase in triglyceride concentration from consuming $30 \mathrm{~g}$ of alcohol a day may increase the risk of coronary heart disease by $1.9 \%(0.5 \%$ to $3.3 \%) ; 4.6 \%$ after adjustment for intraindividual variability in triglyceride concentration.

Estimates of benefits of alcohol owing to haemostatic factors is less robust because fewer experimental studies have assessed these markers and, apart from fibrinogen, the results that link these biomarkers with risk of coronary heart disease are inconsistent. We predict a $7.5 \mathrm{mg} / 100 \mathrm{ml}$ decrease in fibrinogen concentration associated with an intake of $30 \mathrm{~g}$ of alco- hol a day, but this decrease was not significant. Such a decrease, however, would lower the risk of coronary heart disease by $4.3 \%(2.0 \%$ to $6.5 \%)$ based on the Northwick Park study. ${ }^{27}$ Adjusting the estimate for intraindividual variability, the predicted risk reduction for an intake of $30 \mathrm{~g}$ of alcohol a day would be $12.5 \%$.

If high density lipoprotein cholesterol, fibrinogen, and triglycerides act independently to raise or lower the risk of coronary heart disease the overall benefit projected from consuming $30 \mathrm{~g}$ of alcohol a day would be $24.7 \%$ after adjustment for measurement error (table). This probably underestimates the true risk reduction associated with consuming $30 \mathrm{~g}$ of alcohol a day because it ignores the changes in concentrations of plasminogen, Lp(a) lipoprotein, insulin, platelet aggregation, factor VII, and von Willebrand factor.

\section{Discussion}

\section{Summary of main findings}

In this quantitative review we found strong and consistent evidence linking moderate alcohol intake with higher concentrations of high density lipoprotein cholesterol and apolipoprotein A I and lower concentrations of fibrinogen. We also found a weak association between moderate alcohol intake and increased triglyceride concentration. On the basis of published associations between these biomarkers and risk of coronary heart disease we calculated an overall predicted $24.7 \%$ reduction in risk of coronary heart disease associated with an intake of $30 \mathrm{~g}$ of alcohol a day owing to changes in these markers. These data support a causal interpretation of the association between moderate alcohol intake and lower risk of coronary heart disease and suggest that the benefit is mediated in part through several known biological markers of coronary heart disease. The data suggest, however, that other mechanisms are probably involved, but these could not be included in our analysis owing to lack of available experimental data.

\section{Limitations}

Our review has several limitations. Study methods and assay procedures varied. Even among studies that used similar methods changes in biological markers may be modified by differences in genetic predisposition and metabolic ability, diet, smoking patterns, or other lifestyle factors across populations. Unmeasured biological variability in response to moderate alcohol intake would attenuate our overall results. Furthermore, our results are based on experimental studies of short duration; data are not available to test whether similar effects would be found with longer studies. None the less, the $24.7 \%$ reduction in risk of coronary heart disease that we predict on the basis of an intake of $30 \mathrm{~g}$ of alcohol a day is comparable to relative risks reported from several large scale prospective studies of alcohol and coronary heart disease. ${ }^{4}{ }^{9}$

Meta-analyses based only on published data can produce spurious results if null findings or contradictory findings are less likely to be published. However, the intensive effort required for experimental studies of alcohol intake and the assessment of multiple biological outcomes make it less likely that results would go unpublished. In several studies, specific changes in biological markers before and after alcohol 
intake were provided only for factors that substantially changed; those factors not appreciably altered by alcohol were only mentioned. For these data records we assumed the change to be zero.

\section{Alcohol and other factors}

Too few experimental studies included measures of insulin sensitivity for us to be able to summarise them. However, several large cross sectional studies have reported strong positive associations between alcohol and increased insulin sensitivity. ${ }^{33}$

Most of the experimental studies were among young healthy populations. This may provide a better estimate of the true biological effects of moderate alcohol intake as the results are less likely to be influenced by pre-existing lipid abnormalities or preclinical disease. Conversely, the average percentage increase in triglyceride concentration (fig 2) may exaggerate any added health risk associated with moderate alcohol intake as the average baseline triglyceride concentrations were generally low in these populations (mean $96.3 \mathrm{mg} / \mathrm{dl}$ ), and even a small absolute increase in triglyceride concentrations translates to a larger comparative change. The importance of the small increase in triglyceride concentrations is further complicated as increases may not be in the more atherogenic small dense very low density lipoprotein particles.

The association between alcohol and blood pressure has been extensively studied. Although heavy intake (more than four drinks a day) is associated with hypertension $^{35} 36$ no clear dose response has been established at levels of moderate intake ( $30 \mathrm{~g}$ /day). In several prospective studies the relation is U-shaped or $\mathrm{J}_{\text {-shaped }}{ }^{37}$ suggesting a slight decrease in blood pressure among those who consume one drink a day. The overall effect of moderate alcohol intake on blood pressure is likely to be minor; therefore we did not include blood pressure in our review.

\section{Biological mechanisms}

As reviewed in detail elsewhere ${ }^{10}{ }^{38}$ alcohol may directly increase the hepatic production and secretion of apolipoproteins and lipoprotein particles, increase triglyceride lipase concentrations, and decrease removal of circulating high density lipoprotein cholesterol. The increase in production of extrahepatic lipoprotein lipases is in response to increased triglyceride concentrations. Lipolysis of triglyceride rich particles increases the flow of cholesterol to high density lipoprotein particles from circulating very low density lipoprotein remnants and raises overall high density lipoprotein concentration. Although speculative, alcohol may also interfere with the activity of cholesteryl ester transfer protein ${ }^{39} 40$ and reduce the transfer of cholesteryl esters in high density lipoprotein particles to more atherogenic particles. Some investigators have suggested that alcohol may preferentially increase high density lipoprotein-3 particles, which contain apolipoprotein A I and apolipoprotein A II. ${ }^{41}{ }^{42}$ In the two experimental studies that we summarised, which specifically measured the apolipoprotein content of high density lipoprotein particles, both found an increase in high density lipoprotein particles with apolipoprotein A I and apolipoprotein A II, ${ }^{\text {w30 w31 but }}$ Clevidence et al found a similar increase in high density lipoprotein particles only containing apolipo-
Key messages

- Results from observational studies provide strong evidence that moderate alcohol intake lowers risk of coronary heart disease

- Short term trials of alcohol intake show significant changes in concentrations of lipids and clotting factors

- The changes in concentrations of high density lipoprotein cholesterol, fibrinogen, and triglycerides associated with an intake of $30 \mathrm{~g}$ of alcohol a day should reduce risk of coronary disease by $24.7 \%$

- Alcohol intake may be causally related to lower risk of coronary heart disease through changes in lipids and haemostatic factors

protein A I. ${ }^{\text {W31 }}$ There were insufficient data from experimental studies of high density lipoprotein subcomponents to clarify this issue; none the less the importance of high density lipoprotein subfractions in risk prediction may be minimal if total high density lipoprotein concentration is considered. ${ }^{\text {w31 }}$

The effects of alcohol on the thrombolytic and coagulation processes are not as well described. ${ }^{512} 1325$ The mechanism by which alcohol decreases fibrinogen concentration is not known, although the effect has been documented in several large cross sectional studies $^{33} 43$ as well as the small experimental studies described. Alcohol inhibits induced platelet aggregation in several in vitro systems. This effect may be mediated by the inhibition of phospholipase $\mathrm{A}_{2}$, which reduces arachadonic acid release from platelet membranes and decreases thromboxane $\mathrm{A}_{2}$ production. ${ }^{44}$ We did not summarise the effects of alcohol on platelet aggregation owing to large differences in assay methods, but if the effects are causal the subsequent impact on reduced risk of coronary heart disease may be substantial. ${ }^{46} 47$

Although the coefficient of change for several factors was modestly different by sex, few studies were conducted exclusively among women. Decreased first pass metabolism of alcohol among women may accentuate the effects of alcohol on biomarkers of coronary heart disease and thereby reduce the amount of alcohol needed to elicit a response. ${ }^{78-51}$ Therefore the projected overall $24.7 \%$ reduction in coronary heart disease attributed to the effects of an intake of $30 \mathrm{~g}$ of alcohol a day on concentrations of high density lipoprotein cholesterol, fibrinogen, and triglycerides may be achieved at a lower level of intake among women.

\section{Conclusions}

A complete review of the risks and benefits of alcohol intake is beyond the scope of this meta-analysis. Although alcohol intake is associated with an increased risk of breast and aerodigestive cancers, and injury, ${ }^{7} 52$ studies on alcohol and mortality suggest that men and women who consume up to $30 \mathrm{~g}$ of alcohol a day have the lowest overall risk. ${ }^{7-9} 11$ Should non-drinkers be advised to begin drinking? Criqui has argued $^{53}$ that most non-drinkers abstain for a reason (for example, 
religion, previous health conditions, family history of alcoholism) and therefore should not be advised to start drinking. In agreement with this suggestion current recommendations in the United States and the United Kingdom do not encourage alcohol intake but do state that moderate intake can be part of a healthy lifestyle. $^{5455}$ Results from our quantitative review suggest that moderate intake is causally related to lower risk of coronary heart disease through alcohol induced changes in lipids and haemostatic factors.

Contributors: EBR wrote the paper. EBR and KF conducted the search and abstracted the data for the analysis. EBR and PW performed the statistical analysis. MC and MJS reviewed and edited the paper and provided input into the design and analysis for the study. EBR and MJS will act as guarantors for the paper.

Funding: The Europe Alcohol Task Force of the International Life Sciences Institute.

Competing interests: EBR has received both honorariums for speaking at academic conferences and travel expenses from alcohol related organisations.

1 Moore RD, Pearson TA. Moderate alcohol consumption and coronary artery disease: a review. Medicine 1986;65:242-67.

2 Marmot M, Brunner E. Alcohol and cardiovascular disease: the status of the U-shaped curve. BMJ 1991;303:565-8.

3 Maclure M. Demonstration of deductive meta-analysis: ethanol intake and risk of myocardial infarction. Epidemiol Rev 1993;15:328-51.

4 Klatsky AL. Epidemiology of coronary heart disease-influence of alcohol. Alcohol Clin Exp Res 1994;18:88-96.

5 Renaud S, Criqui MH, Farchi G, Veenstra J. Alcohol drinking and coronary heart disease. In: Verschuren PM, ed. Health issues related to alcohol consumption. Washington, DC: ILSI Press, 1993:18-124.

6 Rimm EB, Giovannucci EL, Willett WC, Colditz GA, Ascherio A, Rosner $\mathrm{B}$, et al. A prospective study of alcohol consumption and the risk of coronary disease in men. Lancet 1991;338:464-8.

7 Thun MJ, Peto R, Lopez AD, Monaco JH, Henley SJ, Heath CW Jr, et al. Alcohol consumption and mortality among middle-aged and elderly U.S. adults. N Engl J Med 1997;337:1705-14.

8 Fuchs CS, Stampfer MJ, Colditz GA, Giovannucci EL, Manson JE, Kawachi I, et al. Alcohol consumption and mortality among women. N Engl J Med 1995;332:1245-50

9 Doll R, Peto R, Hall E, Wheatley K, Gray R. Mortality in relation to consumption of alcohol: 13 years' observations on male British doctors. BMJ 1994;309:911-8

10 Moore RD, Smith CR, Kwiterovich PO, Pearson TA. Effect of low-dose alcohol use versus abstention on apolipoproteins A-1 and B. Am J Med 1988:84:884-90

11 Doll R. One for the heart. BMJ 1997;315:1664-8.

12 Reeder VC Jr, Aikens ML, Li XN, Booyse FM. Alcohol and fibrinolytic system. In: Zakhari S, Wassef M, eds. Alcohol and the cardiovascular system, research monograph No 31. Bethesda, MD: National Institutes of Health, National Institute on Alcohol Abuse and Alcoholism, 1996.

13 McKenzie CR, Eisenberg PR. Alcohol, coagulation, and arterial thrombosis. In: Zakhari S, Wassef M, eds. Alcohol and the cardiovascular system, research monograph No 3. Bethesda, MD: National Institutes of Health, National Institute on Alcohol Abuse and Alcoholism, 1996

14 Klatsky AL, Armstrong MA, Friedman GD. Alcohol and mortality. Ann Intern Med 1992;117:646-54

15 Verschuren PME. Health issues related to alcohol consumption. Washington, DC: ILSI Press, 1993:329.

16 Mosteller F, Chalmers TC. Some progress and problems in meta-analysis of clinical trials. Stat Sci 1992;7:227-36.

17 Smith SJ, Caudill SP, Steinberg KK, Thacker SB. On combining dose-response data from epidemiological studies by meta-analysis. Stat Med 1995; 14:531-44.

18 Rosner B, Spiegelman D, Willett WC. Correction of logistic regression relative risk estimates and confidence intervals for random within-person measurement error. Am J Epidemiol 1992;136:1400-13.

19 Willett WC. Nutritional epidemiology. New York: Oxford University Press, 1990.

20 Marckmann P, Sandstrom B, Jespersen J. The variability of and associations between measures of blood coagulation, fibrinolysis and blood lipids. Atherosclerosis 1992;96:235-44

21 Rosenson RS, Tangney CC, Hafner JM. Intraindividual variability of fibrinogen levels and cardiovascular risk profile. Arterioscler Thromb 1994;14:1928-32.

22 Meade TW, Chakrabarti R, Haines AP, North WR, Stirling Y. Characteristics affecting fibrinolytic activity and plasma fibrinogen concentrations. BMJ 1979;1:153-6.

23 Ridker PM, Vaughan DE, Stampfer MJ, Glynn RJ, Hennekens CH. Association of moderate alcohol consumption and plasma concentration of endogenous tissue-type plasminogen activator. JAMA 1994;272: 929-33.

24 Folsom AR, Wu KK, Davis CE, Conlan MG, Sorlie PD, Szklo M. Population correlates of plama fibrinogen and factor VII, putative cardiovascular risk factors. Atherosclerosis 1991;91:191-205.
25 Renaud SC, Ruf JC. Effects of alcohol on platelet functions. Clin Chimica Acta 1996;246:77-89.

26 Meade TW, Mellows S, Brozovic M, Miller GJ, Chakrabarti RR, North WR, et al. Haemostatic function and ischaemic heart disease: principal results of the Northwick Park heart study, Lancet 1986:2:533-7.

27 Ridker PM, Vaughan DE, Stampfer MJ, Manson JE, Hennekens CH. Endogenous tissue-type plasminogen activator and risk of myocardial infarction. Lancet 1993;341:1165-8.

28 Ernst E, Resch KL. Fibrinogen as a cardiovascular risk factor: a meta-analysis and review of the literature. Ann Intern Med 1993;118: 956-63.

29 Stampfer MJ, Sacks FM, Salvini S, Willett WC, Hennekens CH. A prospective study of cholesterol, apolipoproteins, and the risk of myocardial infarction. N Engl J Med 1991;325:373-81

30 Stampfer MJ, Krauss RM, Ma J, Blance PJ, Holl LG, Sacks FM, et al. A prospective study of triglyceride level, low-density lipoprotein particle diameter, and risk of myocardial infarction. JAMA 1996;276:882-8.

31 Friedman LA, Kimball AW. Coronary heart disease mortality and alcohol consumption in Framingham. Am J Epidemiol 1986;124:481-9.

32 Jacobs DR Jr, Mebane IL, Bangdiwala SI, Criqui MH, Tyroler HA, for the Lipid Research Clinics. High density lipoprotein cholesterol as a predictor of cardiovascular disease mortalilty in men and women: the follow-up study of the lipid research clinics prevalence study. Am J Epidemiol 1990;131:32-47.

33 Kiechl S, Willeit J, Poewe W, Egger G, Oberhollenzer F, Muggeo M, et al. Insulin sensitivity and regular alcohol consumption: large, prospective, cross sectional population study (Bruneck study). BMJ 1996;313:1040-4.

34 Vitelli LL, Folsom AR, Shahar E, Winkhart SP, Shirnakawa T, Stevens J, et al. Association of dietary composition with fasting serum insulin level-the ARIC study. Nutr Metab Cardiovasc Dis 1996;6:194-202.

35 Ascherio A, Rimm EB, Giovannucci EL, Colditz GA, Rosner B, Willett WC, et al. A prospective study of nutritional factors and hypertension among US men. Circulation 1992;86:1475-84

36 Puddey IB, Beilin LJ, Vandongen R, Rouse IL, Rogers P. Evidence for a direct effect of alcohol consumption on blood pressure in normotensive men. A randomized controlled trial. Hypertension 1985;7:707-13.

37 Camargo CA Jr, Rimm EB. Epidemiologic research on moderate alcohol consumption and blood pressure. Alcohol and cardiovascular system, research monograph 31. Bethesda, MD: National Institute on Alcohol Abuse and Alcoholism, 1996:25-62. (Publication No 96-4133.)

38 Savolainen MJ, Kesaniemi YA. Effects of alcohol on lipoproteins in relation to coronary heart disease. Curr Opin Lipidol 1995;6:243-50.

39 Hannuksela M, Marcel YL, Kesaniemi YA, Savolainen MJ. Reduction in the concentration and activity of plasma cholesteryl ester transfer protein by alcohol.J Lipid Res 1992;33:737-44.

40 Hannuksela ML, Rantala M, Kesaniemi YA, Savolainen MJ. Alcoholinduced redistribution of cholesteryl ester transfer protein (CETP) between lipoproteins. Circulation 1992;86(suppl):2756. (Abstract.)

41 Branchi A, Rovellini A, Tomella C, Sciariada L, Torri A, Molgora M, et al. Association of alcohol consumption with HDL subpopulations defined by apolipoprotein A-I and apolipoprotein A-II content. Eur J Clin Nutr 1997; 1997:362-5.

42 Puchois P, Ghalim N, Zylberberg G, Fievet P, Demarquilly C, Fruchart JC. Effect of alcohol intake on human apolipoprotein A-I containing lipoprotein subfractions. Arch Intern Med 1990;150:1638-41.

43 Meade TW, Imeson J, Stirling Y. Effects of changes in smoking and other characteristics on clotting factors and the risk of ischaemic heart disease. Lancet 1987;2:986-8.

44 Rand ML, Gross PL, Jakowec DM, Packham MA, Mustard JF. In vitro effects of ethanol on rabbit platelet aggregation, secretion of granule contents, and cyclic AMP levels in the presence of prostacyclin. Thromb Haemostasis 1989:61:254-8.

45 Stubbs CD, Rubin R. Effect of ethanol on platelet phospholipase A2. Lipids 1992;27:255-60.

46 Elwood PC, Renaud S, Sharp DS, Beswick AD, O'Brien JR, Yarnell JWG. Ischemic heart disease and platelet aggregation: the Caerphilly collaborative heart disease study. Circulation 1991;83:38-44.

47 Furman MI, Benoit SE, Barnard MR, Valeri CR, Borbone ML, Becker RC, et al. Increased platelet reactivity and circulating monocyte-platelet aggregates in patients with stable coronary artery disease. J Am Coll Cardiol 1998;31:352-8.

48 Stampfer MJ, Colditz GA, Willett WC, Speizer FE, Hennekens CH. A prospective study of moderate alcohol consumption and the risk of coronary disease and stroke in women. N Engl J Med 1988;319:267-73.

49 Rosenberg L, Slone D, Shapiro S, Kaufman DW, Miettinen OS, Stolley PD. Alcoholic beverages and myocardial infarction in young women. Am J Public Health 1981;71:82-5.

50 Klatsky AL, Armstrong MA, Friedman GD. Red wine, white wine, liquor, beer, and risk of coronary artery disease hospitalization. Am J Cardiol 1997;80:416-20.

51 Rehm JT, Bondy SJ, Sempos CT, Vuong CV. Alcohol consumption and coronary heart disease morbidity and mortality. Am J Epidemiol 1997; 146:495-501

52 Smith-Warner SA, Spiegelman D, Yaun S-S, Adami HO, van den Brandt PA, Folsom AR, et al. Alcohol and breast cancer in women: a pooled analysis of cohort studies. JAMA 1998;279:535-40.

53 Criqui $\mathrm{MH}$. Alcohol and coronary heart disease risk: implications for public policy.J Stud Alcohol 1997;58:453-4

54 Food and Nutrition Board. Recommended dietary allowances, 10th revised ed. Washington, DC: National Academy of Sciences, 1989.

55 Department of Health. Interdepartmental working group. Sensible drinking. Wetherby: DoH, 1995.

(Accepted 7 September 1999) 